\title{
25 Research Soure \\ Intellectual Decline in a Patient with Migraine and APT1A2 Mutation: A Case Report
}

\section{Pian Wang}

Chengdu Fifth Peoples' Hospital

Yan-Rong Yang

Chengdu Fifth Peoples' Hospital

Hong-Bo Zhang

Chengdu Fifth Peoples' Hospital

Jiang-Hong Wang

Chengdu Fifth Peoples' Hospital

Yan Wang ( $\boldsymbol{D}$ 17340085006@163.com )

Chengdu Fifth Peoples' Hospital https://orcid.org/0000-0002-9744-4382

\section{Case report}

Keywords: Hemiplegic migraine, Intellectual disability, ATP1A2 mutation, younger age

Posted Date: February 5th, 2021

DOI: https://doi.org/10.21203/rs.3.rs-180997/v1

License: (c) (1) This work is licensed under a Creative Commons Attribution 4.0 International License. Read Full License 


\section{Abstract}

Background: Hemiplegic migraine $(\mathrm{HM})$ is a rare type of migraine with aura. Some reports have described the clinical manifestations in HM patients with the ATP1A2 mutation. But the impact of the ATP1A2 mutation on intelligence in HM patients has not been evaluated in detail. Here we report a patient with intellectual decline in specific area.

Case presentation: A 15-year-old boy with an aura that included disturbances in consciousness, associated with fever, vomiting, hemiplegia, and aphasia. He was diagnosed HM with the ATP1A2 mutation before. He had trouble in mathematics and depicting three-dimensional things.

Conclusions: The HM with ATP1A2 patient could develop permanent intellectual disabilities. Therefore, the intelligence quotient should be carefully and comprehensively evaluated.

\section{Background}

Hemiplegic migraine (HM) is a rare type of migraine with aura, with an incidence of $0.1 \%$ in the European population [1, 2]. The specific clinical manifestations include completely reversible limb weakness, paresthesia, aphasia, etc [3]. HM is divided into two types: sporadic and familial based on its occurrence in first and second degree relatives [4]. This diagnosis is not definitive since it changes from sporadic hemiplegic migraine (SHM) to familial hemiplegic migraine (FHM) once its presence is confirmed in relatives. $\mathrm{HM}$ is a monogenic disorder with incomplete penetrance [5]. The confirmed pathogenic genes are mapped to be CACNAIA, ATP1A2, and SCN1A [5]. Some reports have described the clinical manifestations in HM patients with the ATP1A2 mutation and indicated that they are more prone to disturbances in consciousness, fever, epilepsy [6], and sometimes experience psychotic aura [7]. However, the impact of the ATP1A2 mutation on intelligence in HM patients has not been evaluated in detail. We carefully assessed the cognitive function of a 15-year-old boy who was diagnosed with HM and had an ATP1A2 mutation. We found that there was a decline in certain intellectual categories in this patient.

\section{Case Presentation}

In 2009, a 4-year-old developmentally normal boy, studying in kindergarten (born without birth asphyxia) was brought with sudden onset of vomiting, convulsions, crying, fever, and restlessness after intake of food. At admission in the emergency department, he developed altered sensorium. The boy was thus transferred to the intensive care unit (ICU) for further treatment. In the ICU, a lumbar puncture, magnetic resonance imaging (MRI) of the brain, and blood investigations were performed. All test results were normal. A diagnosis of "viral encephalitis" was considered and he was treated for the antiviral therapy. The family was unable to recall the specific antiviral medications administered to him. His fever settled after 4 days and he opened his eyes after 6 days. After 2 weeks, he could talk briefly but had not started walking yet. After 1 month, he could speak and walk normally. 
By March 2018, he had experienced four similar episodes. All episodes were precipitated by increased intake food, with disturbances in consciousness, associated with fever, vomiting, hemiplegia, and aphasia. He was diagnosed as having "viral encephalitis" at least twice in two different hospitals. In 2010, he was diagnosed as having "epilepsy" following an abnormal electroencephalogram (EEG) report and was initiated on oral phenobarbital at $0.1 \mathrm{~g}$ that was administered once a day. After taking phenobarbital for 3 years, he was asked to discontinue its use after a repeat EEG examination because there were no further similar episodes.

In July 2018, wanted to finger out the episodes, boy was referred to another hospital, where he underwent whole-exome gene sequencing. The presence of a mutation in the ATP1A2 gene was confirmed and he was diagnosed with HM. He was treated with flunarizine and nimodipine subsequently. He stopped taking his medications after developing hypologia, sweating, decreased night sleep, increased daytime sleep, and rash.

In May 2020, he suffered from right limb hemiplegia, aphasia, altered sensorium, fever, and vomiting after increased food intake, and was referred to our hospital. Physical examination revealed a body temperature of $39^{\circ} \mathrm{C}$ and a Glasgow Coma Scale of $9 / 15$. Based on his medical history and the presentation at the time of admission, we performed a lumbar puncture, brain MRI, EEG and blood investigations including biochemistry, and coagulation tests after admission. His cerebrospinal fluid (CSF) pressure was $120 \mathrm{mmH} 20$. And the rest of the CSF analysis was normal, too. His brainMRI showed increased cortical sulci in the left cerebral hemisphere on the flair sequences (figure 1). EEG shows abnormal slow waves were present on the left frontal area, central area, parietal area, with bilateral epileptiform discharge (Fig. 2). Blood test results revealed an increase in the percentage of white blood cells and neutrophils. He was treated with mannitol to reduce edema and cefuroxime for infection control. His fever settled 3 days later, physical activity on the right side improved and he could get out of bed, but he continued to be aphasic. After 6 days in the hospital, he developed sudden left-sided gaze palsy and convulsions after an increase in food intake. We added $250 \mathrm{mg}$ of levetiracetam orally, twice daily. He was discharged from our hospital after 10 days of treatment. At discharge, he had no fever, and his right limb muscle strength was $5 / 5$, but he could only say some simple words. One month later, he was followed up in the outpatient clinic when he was able to walk and communicate normally.

During the hospitalization, his mother was probed in detail about his condition before hospitalization. His mother felt that his intellect was worse than that of his peers, especially in mathematics. He could communicate with classmates normally and interact with his friends on his own. He was very good in language but not in math. He could only solve the most basic addition and subtraction problems. When he followed up in the outpatient clinic,MoCA test was perfomed. His MoCA is 25(3/3/1/1/1/2/1/2/5/6). His mother disclosed that he liked to draw but had trouble depicting three-dimensional things (Fig. 3). On perusal of his family history, his father was noted to have died of brainstem hemorrhage in 2014. There was no history of headaches in his father before his death. Neither his mother nor his grandparents have migraines or other systemic diseases. 


\section{Discussion}

As a rare kind of migraine with aura, HM with ATP1A2 gene mutation is described in only a few case reports. Some scholars have summarized the clinical characteristics of HM with ATP1A2 mutation [1, 3, 6, 8]. In the present case, excessive food intake was the only trigger. HM can be triggered by minor head trauma [1, 6], common cold, fatigue, emotional stress, etc [9]. The patient became comatose immediately after the onset of fever. This finding was described in other cases as well [9-14].

Approximately $15 \%$ of FHM patients suffer from coma [1]. In addition, $47 \%$ of $\mathrm{HM}$ patients have altered sensorium associated with fever [1]. Although experts think epilepsy occurs independently from migraine attacks [1, 15], it is one of the most severe symptoms in patients with HM [16]. There are some sporadic reports that some HM patients with the APT1A2 mutations, as in our patient, have a younger age of onset with less than one attack per year and an aura lasting more than 72 hours $[9,14]$. This provides new clues for the future diagnosis of the disease.

Since the patient became unconscious soon after the onset of fever, we performed a lumbar puncture. Similar to previous reports, in the present case, the patient's CSF pressure, hematological and biochemical analysis were all normal. Although there have been previous case reports about the use of acyclovir $[6,8$, $10,13,14]$, we believed that the patient's fever and coma were clinical manifestations of this type of HM, rather than viral encephalitis, and did not use any antiviral treatment. Thus, antiviral treatment is not recommended in the absence of definitive markers of intracranial infection. Symptomatic treatment is essential. The patient's MRI showed brain edema, which was treated using mannitol. When he developed epilepsy, levetiracetam was used [17]. There is insufficient evidence for long-term anti-epileptic treatment, and we believed that specific treatment plans should be made based on the patient's symptoms and EEG findings.

The most interesting thing about our patient was that his intellectual disabilities were different from others. Although he went to school and had normal social skills, his computational ability and threedimensional spatial awareness were significantly lower than those of children in the same age group. It was previously speculated that HM could cause irreversible brain damage [1]. The patient's MRI brain and EEG were completely normal during the interictal period. It is speculated that the boy's intellectual disability could have had another pathogenesis. It has been reported that writing function improves after using memantine and dextromethorphan in patients with the ATP1A2 mutation and that they benefit from $\mathrm{N}$-methyl-D-aspartate receptor antagonists [18]. However, this is only speculation because the patient did not provide consent for further investigations to determine the variant protein related to the ATP1A2 mutation. In addition, magnetic resonance spectroscopy (MRS) had not been performed during hospitalization. The reason for the intellectual disability in this patient needs to be investigated further.

In summary, some HM patients with ATP1A2 mutations may present with fever and coma at the onset of disease. If the cerebrospinal fluid test results are normal, antiviral therapy is not recommended. The patient could develop intellectual disabilities, which might manifest as a decline in computational and a 
poor sense of three-dimensional spatial abilities. Therefore, the intelligence quotient of HM patients should be carefully and comprehensively evaluated.

\section{List Of Abbreviations}

EEG - electroencephalogram

FHM - familial hemiplegic migraine

$\mathrm{HM}$ - Hemiplegic migraine

ICU - Intensive care unit

MRI - Magnetic resonance imaging

SHM - sporadic hemiplegic migraine

TCD - transcranial doppler

\section{Declarations}

Consent for publication:

The patient's mother signed the informed consent form for publication of this case report and accompanying images.

Ethics approval and consent to participate]

Because the patient is under 18 years old, the patient's mother signed the informed consent form.

Competing interests:

non-financial competing interests.

Funding:

no

Authors' contributions: 


\begin{tabular}{|lll|}
\hline Name & Role & Contribution \\
\hline Pian Wang & Author & Executing $\llbracket$ writing the manuscript \\
\hline Yan-Rong Yang & Author & Executing $\llbracket$ writing the manuscript \\
\hline Hong-bo Zhang & Author & Figure description \\
\hline Jiang-Hong Wang & Author & Figure description \\
\hline Yan Wang & Author & Review and figure description \\
\hline
\end{tabular}

\section{Acknowledgements:}

Not applicable

\section{References}

1. Russell MB, Ducros A (2011) Sporadic and familial hemiplegic migraine: pathophysiological mechanisms, clinical characteristics, diagnosis, and management. Lancet Neurol 10:457-470.

2. Lykke Thomsen L, Kirchmann Eriksen M, Faerch Romer S, Andersen I, Ostergaard E, Keiding N, Olesen J, Russell MB (2002) An epidemiological survey of hemiplegic migraine. Cephalalgia 22:361-375.

3. Di Stefano V, Rispoli MG, Pellegrino N, Graziosi A, Rotondo E, Napoli C, Pietrobon D, Brighina F, Parisi $P$ (2020) Diagnostic and therapeutic aspects of hemiplegic migraine. J Neurol Neurosurg Psychiatry 91:764-771.

4. Headache classification committee of the International Headache Society (IHS) The international classification of headache disorders, 3rd edition (2018) Cephalalgia 38:1-211.

5. Sutherland HG, Griffiths LR (2017) Genetics of migraine: Insights into the molecular basis of migraine disorders. Headache 57:537-569.

6. Martinez E, Moreno R, Lopez-Mesonero L, Vidriales I, Ruiz M, Guerrero AL, Tellería JJ (2016) Familial hemiplegic migraine with severe attacks: a new report with atp1a2 mutation. Case Rep Neurol Med 2016:3464285.

7. Barros J, Mendes A, Matos I, Pereira-Monteiro J (2012) Psychotic aura symptoms in familial hemiplegic migraine type 2 (ATP1A2). J Headache Pain 13:581-585.

8. Du Y, Li C, Duan FJ, Zhao C, Zhang W (2020) Early treatment in acute severe encephalopathy caused by ATP1A2 mutation of familial hemiplegic migraine type 2: Case report and literature review. Neuropediatrics 51:215-220.

9. Tang W, Zhang M, Qiu E, Kong S, Li Y, Liu H, Dong Z, Yu S (2019) A Chinese family with familial hemiplegic migraine type 2 due to a novel missense mutation in ATP1A2. Cephalalgia 39:1382-1395. 
10. Murphy OC, Merwick A, O'Mahony O, Ryan AM, McNamara B (2018) Familial hemiplegic migraine with asymmetric encephalopathy secondary to ATP1A2 mutation: A case series. J Clin Neurophysiol 35:e3-e7.

11. Hiekkala ME, Vuola P, Artto V, Häppölä P, Häppölä E, Vepsäläinen S, Cuenca-León E, Lal D, Gormley P, Hämäläinen E, Ilmavirta M, Nissilä M, Säkö E, Sumelahti ML, Harno H, Havanka H, Keski-Säntti P, Färkkilä M, Palotie A, Wessman M, Kaunisto MA, Kallela M (2018) The contribution of CACNA1A, ATP1A2 and SCN1A mutations in hemiplegic migraine: A clinical and genetic study in Finnish migraine families. Cephalalgia 38:1849-1863.

12. Schwarz G, Anzalone N, Baldoli C, Impellizzeri M, Minicucci F, Comi G, Colombo B (2018) Pediatric sporadic hemiplegic migraine (ATP1A2 gene): a case report and brief literature review. Neurol Sci 39:69-71.

13. Merwick A, Fernandez D, McNamara B, Harrington H (2013) Acute encephalopathy in familial hemiplegic migraine with ATP1A2 mutation. BMJ Case Rep 2013:bcr2013009750.

14. Pelzer N, Blom DE, Stam AH, Vijfhuizen LS, Hageman A, van Vliet JA, Ferrari MD, van den Maagdenberg A, Haan J, Terwindt GM (2017) Recurrent coma and fever in familial hemiplegic migraine type 2. A prospective 15-year follow-up of a large family with a novel ATP1A2 mutation. Cephalalgia 37:737-755.

15. Costa C, Prontera P, Sarchielli P, Tonelli A, Bassi MT, Cupini LM, Caproni S, Siliquini S, Donti E, Calabresi P (2014) A novel ATP1A2 gene mutation in familial hemiplegic migraine and epilepsy. Cephalalgia 34:68-72.

16. Carreno O, Corominas R, Serra SA, Sintas C, Fernández-Castillo N, Vila-Pueyo M, Toma C, Gené GG, Pons R, Llaneza M, Sobrido MJ, Grinberg D, Valverde MÁ, Fernández-Fernández JM, Macaya A, Cormand B (2013) Screening of CACNA1A and ATP1A2 genes in hemiplegic migraine: clinical, genetic, and functional studies. Mol Genet Genomic Med 1:206-222.

17. Dannenberg F, Prager C, Schmidt F, Tietze A, Bittigau P, Kaindl AM (2020) Intravenous nimodipine treatment for severe episode of ATP1A2 hemiplegic migraine. Pediatr Neurol 112:71-72.

18. Ueda K, Serajee F, Huq AM (2018) Clinical benefit of nmda receptor antagonists in a patient with ATP1A2 gene mutation. Pediatrics 141:S390-S394.

\section{Figures}



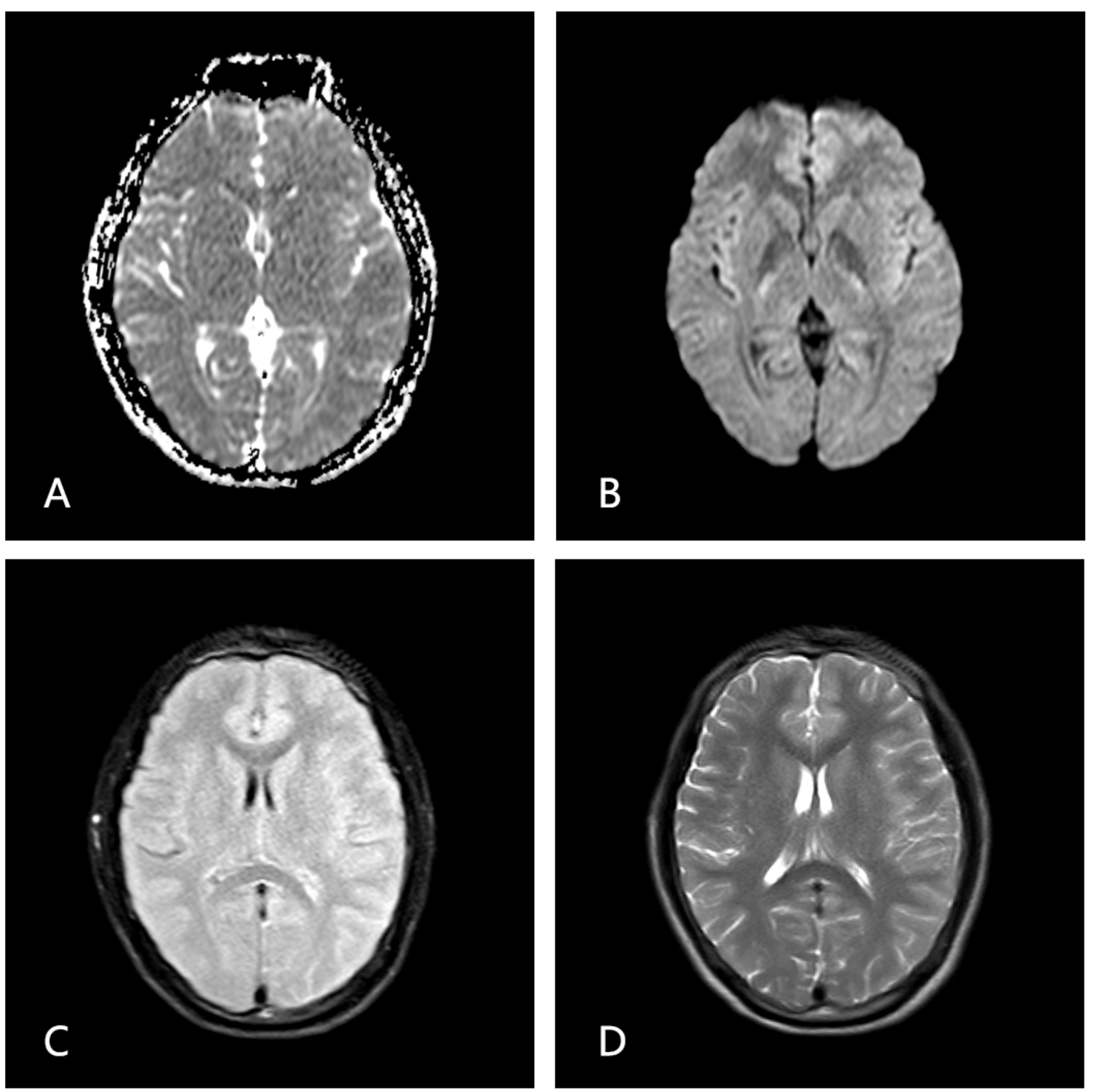

Figure 1

The ADC (A), DWI (B) and T2 (D) are negative, but FLAIR (C) shows increased cortical sulci in the left cerebral hemisphere 


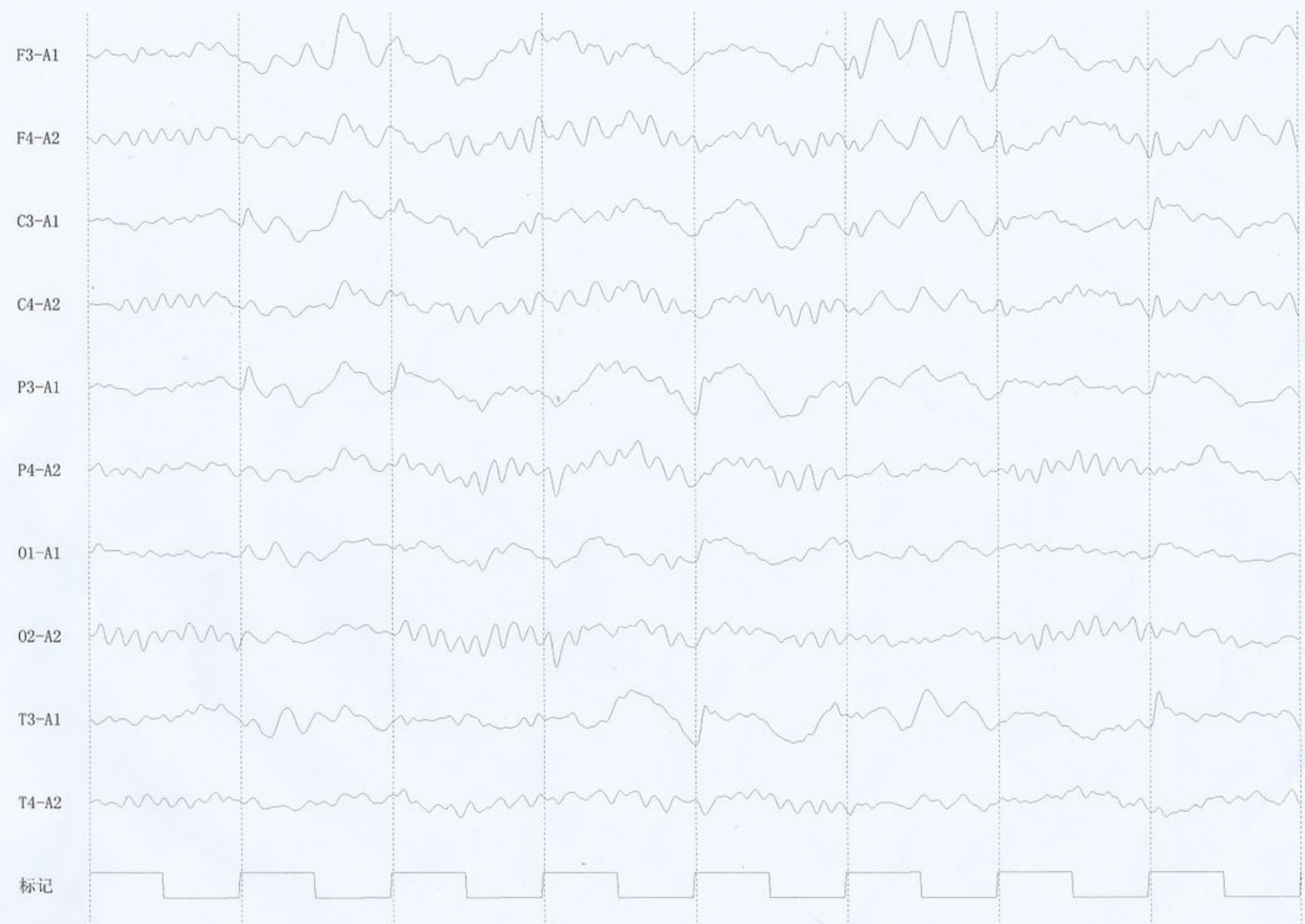

Figure 2

Abnormal slow waves were present on the left frontal area, central area, parietal area, with bilateral epileptiform discharge. 


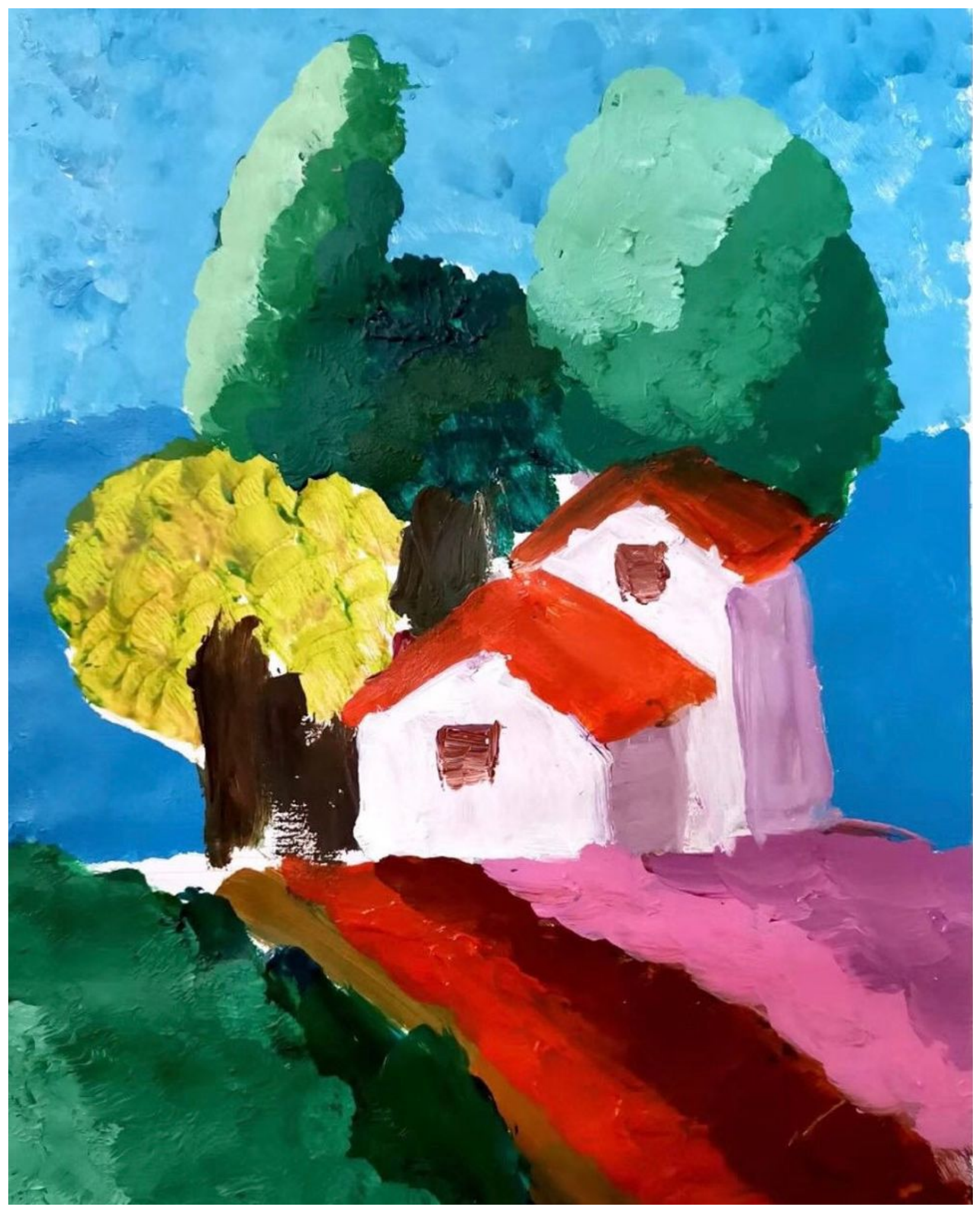

Figure 3

The patient's painting 